\title{
Phylogenetic analysis of HDV isolates from HBsAg positive patients in Karachi, Pakistan
}

\author{
Shadab Perveen ${ }^{1}$, Muhammad Israr Nasir ${ }^{2}$, Syed M Shahid ${ }^{1}$, Abid Azhar ${ }^{1}$ and Obaid Yusuf Khan ${ }^{3^{*}}$
}

\begin{abstract}
Background: In spite of a high occurrence of Hepatitis Delta in the province of Sindh in Pakistan, no genetic study of Hepatitis Delta virus (HDV) isolates from this region was carried out. The aim of this study is to analyze the genetic proximity within local HDV strains, and relationship with other clades of HDV, using phylogenetic analysis.

Results: Phylogenetic analysis of nucleotide sequences of the Hepatitis Delta Antigen (HDAg) RO region obtained in this study, showed considerable diversity among the local strains with a potential subgroup formation within clade I. The multiple sequence alignment of predicted amino acids within clade I showed many uncommon amino acid substitutions within some conserved regions that are crucial for replication and assembly of HDV.

Conclusions: The studied strains showed a range of genetic diversity within HDV clade I. There is clustering of sequences into more than one group, along with formation of potential subgroup within clade I. Clustering shows the genetic closeness of strains and indicates a common origin of spread of HDV infection. Further phylogenybased studies may provide more information about subgroup formation within clade I and may be used as an effective tool in checking and/or preventing the spread of hepatitis D virus infection in this region.
\end{abstract}

Keywords: Hepatitis D virus, HDV- clades, Phylogeny, HDAg

\section{Background}

Hepatitis, the inflammation of liver can be caused by variety of viruses such as Hepatitis $\mathrm{A}, \mathrm{B}, \mathrm{C}, \mathrm{D}$ and $\mathrm{E}$ viruses. Among these some are food borne, while some are transmitted only through contaminated blood and blood products [1].

Hepatitis D virus (HDV) or Delta was first identified as an antigen in liver biopsies of chronic hepatitis B infected patients. This antigen was named as Delta antigen that required mandatory existence of Hepatitis $B$ virus (HBV). The source of this antigen was later identified as a RNA virus that was a satellite virus of HBV. Coexistence of HDV with HBV increases the rate of cirrhosis and hepatocellular carcinoma many folds as compared to hepatitis B alone. HDV has two modes of infection, co-infection or a super infection $[2,3]$.

Hepatitis delta virus (HDV) is the smallest RNA satellite virus identified to date consisting of 1700 nucleotides $[4,5]$. The HDV RNA genome is divided into two regions; a viroid-like conserved region that is infectious

\footnotetext{
* Correspondence: oykhan@uok.edu.pk

${ }^{3}$ Department of Genetics, University of Karachi, Karachi, Pakistan

Full list of author information is available at the end of the article
}

and does not encode any protein while the other part of genome codes for the only known functional protein called the Hepatitis Delta Antigen (HDAg). HDAg is known to exist in two essential forms [4,5], the smaller S-HDAg (195 a.a; 24KDa) and the larger L-HDAg (214a. a; $27 \mathrm{KDa}$ ). These two proteins are encoded by a single gene with the larger protein arising as a result of extension of the coding sequence due to RNA editing at the amber/W site of HDV antigenomic RNA $[4,6,7]$.

The HDV RNA from nucleotide 900 to $1260 \mathrm{bp}$ (corresponding to amino acids 111-214 of HDAg) encompasses several important functional elements and has been used to explore genetic diversity among Hepatitis D Virus $[5,8]$. This includes one of the two RNA binding domain comprising Arginine Rich Motif (ARM) extending from amino acid position138-145, and its facilitating region Helix loop helix motif (HLH) from 111-137 amino acids. The Glycine-proline rich region (coiled-coil motif), is a characteristic feature of transcriptional factors and facilitates greatly in formation of HDAg-RNA complex $[8,9]$. The amino acids at C-terminal position of S-HDAg carry the epitope region which has a highly conserved GAPGGG domain which acts as a effective
Ciomed Central

(c) 2012 Perveen et al.; licensee BioMed Central Ltd. This is an Open Access article distributed under the terms of the Creative Commons Attribution License (http://creativecommons.org/licenses/by/2.0), which permits unrestricted use, distribution, and reproduction in any medium, provided the original work is properly cited. 
immunogenic domain in humans [10]. Other features include a crucial Serine- 177 phosphorylation site that is indispensible for HDV RNA replication and editing process [9]. An essential nuclear export signal (NES) region extends from amino acids 198-210 [11]. Within the NES, exists a clathrin box-binding domain from amino acids 199-203 which is responsible for clathrinmediated endocytosis of HDV-RNA complex from nucleus to cytoplasm of infected hepatocytes. The amber/W-196 residue is indicated as the site for RNA editing that leads to formation of L-HDAg which inhibits HDV RNA replication and initiates viral assembly [7]. An isoprenylation site corresponding to C-terminal 19 amino acids of L-HDAg, undergoes farnesylation via Cystein-211, allowing export of L-HDAg to cytoplasm [9]. In the cytoplasm, the L-HDAg interacts with Hepatitis B surface antigen (HBsAg) in the form of clathrinmediated vesicles at the endoplasmic reticulum, resulting in HDV virion maturation [11].

HDV genome is reported to undergo a higher range of genetic variability among all other RNA viruses. Previously, the genetic variability of HDV was based on the Restriction-Fragment Length Polymorphism (RFLP) of the R0 region of HDAg which assigned the viruses into genotypes I, II and III, while phylogenetic analysis allocates the HDV viruses to eight groups or clades (I to VIII) [5]. The heterogeneity in nucleotide sequence of the R0 region (delta antigen-coding region in the antigenomic strand of HDV RNA) is less than 14 to $15.7 \%$ among different isolates of the same genotypes, while between genotypes the heterogeneity ranges from 19 to $38 \%$. About $30 \%$ divergence is observed in the amino acid sequences from different genotypes [12]. HDV genotype III (clade-3) is the most divergent group among HDV isolates [12,13].

Genotype I includes most of the European, North American, African and some Asian HDV isolates. Genotype II has been found in Japan and Taiwan, while genotype III has been found exclusively in South America. HDV genotype I-associated disease patterns are highly variable, ranging from severe to mild. Genotype II has been found only in East Asia and has been suggested to be associated with a milder disease course. Genotype III is particularly severe and results into fulminant hepatitis $[2,14]$.

Hepatitis B and Hepatitis D dual infection is one of the serious viral health problem in Pakistan specifically in the province of Sindh where its incidence rate has reached up to about $67 \%$ [15]. The main cause of this spread is the unrestricted use of infected syringes and razor blades $[14,16]$.

Even with such a high prevalence rate of HDV in this region, to the best of our knowledge, no phylogeneticbased study has been carried out on the predominant HDV isolates of Pakistan.
The aim of this study is to perform a preliminary analysis of the genetic relatedness of predominant Pakistani HDV isolates, to strains reported from different countries, assigned into the eight clades. The study will help greatly in identifying the variants present in our population and help in understanding the origin and spread of HDV infection in Sindh, Pakistan.

\section{Results}

HDV isolates from patients diagnosed with chronic HDV were analyzed at the genetic level to determine the evolutionary relatedness of Pakistan HDV isolates to the reported strains of different countries and clades. This study was expected to identify new genetic variants that may exist in the local HDV strain.

\section{RFLP analysis}

Nested PCR amplified DNA digested with restriction enzyme SmaI produced two bands of 179 and $250 \mathrm{bp}$, demonstrating that all samples belonged to genotype I $[5,17]$. A representative sample of the digests is shown in (Figure 1).

\section{Phylogenetic analysis}

The phylogenetic tree constructed by using the Maximum Likelihood method based on the GTR + G model is shown in Figure 2, and Bayesian method is shown in Figure 3.

The phylogenetic analysis of C-terminal part of LHDAg of isolates from this study places all our isolates within the largest clade I of HDV with a significant bootstrap confidence value of $92 \%$ (ML) and posterior probability 100\% (BEAST v1.7.2). This observation supports our PCR-RFLP results (Figure 1), where all isolates screened produced the DNA digest bands that are indicative of genotype I [5,17].

Further observations have revealed that isolates with accession number JN798541, JN798544, JN798545, JN798537, JN798546, JN798535, JN798549, JN798539 and JN798551 (designated as Pak. isolates group A) are closely clustered with a higher bootstrap value of $67 \%$ (ML) and posterior probability 99\% (BEAST v1.7.2), indicating the existence of a potential subgroup within clade I. Other isolates are showing association with some geographically distant isolates: JN798538 and JN798552 are closer in the tree to an isolate from Mongolia (M58629), JN798530 lies close to sequences from China and Japan and sequence JN 798533 is in proximity to sequences from the Middle East (Figure 2 and Figure 3).

Majority of our isolates including the potential subgroup Pak. group A, seem closer to the isolate from US on both phylogenetic trees. Outside Pak. group A, most of our isolates are forming two clusters but with lower bootstrap values. 


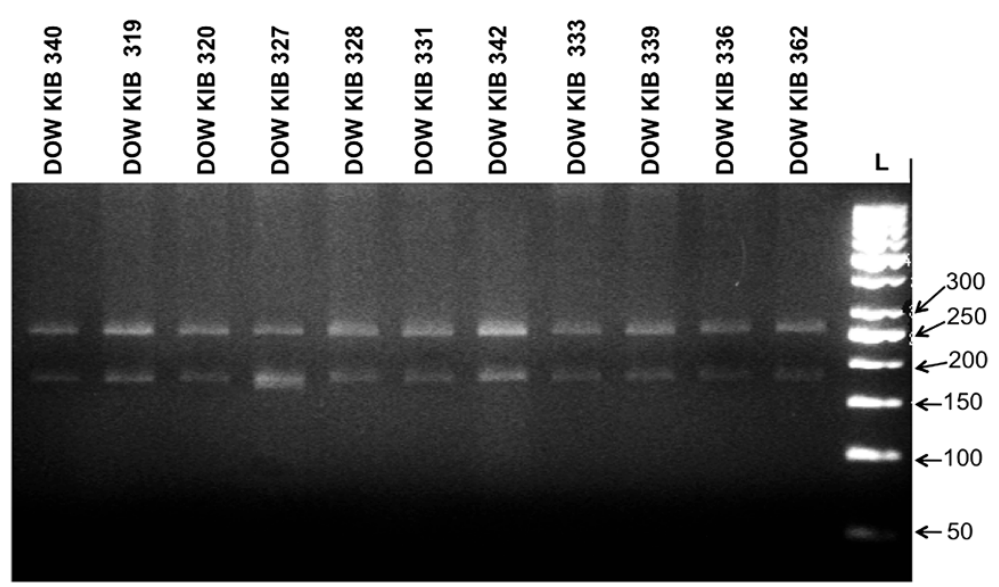

Figure 1 HDV genotype characterization by RFLP of amplified R0 region for some strains of HDV isolated from serum of HDV patients. The Smal digest produced bands of 179 and 250 bp indicating genotype I. The Smal site is present in the immunogenic region corresponding to nucleotides base pair 1066-1073 of HDAg.

\section{Amino acid sequence analysis}

The predicted amino acid sequence (111-214) of amplified region of our isolates corresponding to nucleotide 856-1282, were compared with reference sequences of Clade I, to check/confirm presence of all respective essential and conserved protein domains in this amplified region (Figure 4). All of the studied isolates express CRPQ region at C-terminal end of L-HDAg. CRPQ residues are specific for clade I and used to differentiate clade I from other clades of HDV [4,11]. This observation supports the phylogenetic outcome at the nucleotide level which had placed the Pakistani isolates into clade I.

It was also observed that the isolates which formed the subgroup within clade I on phylogenetic analysis specifically carry amino acid mutation/substitutions that are unusual to clade I (Figure 4).

\section{Discussion}

The current study is the first phylogenetic analysis of HDV isolates from Pakistan. This evolutionary analysis places all of the studied isolates within the largest HDV clade I. Majority of the Pakistani isolates form a phyletic subgroup that branches away from most clade I isolates with a significant bootstrap and posterior probability value. This group is therefore more distant from most clade I sequences, but interestingly is more close to the clade I sequences from geographically distant areas (Italy and USA). Within this group, three clusters can be seen forming, one of which shows higher bootstrap and posterior probability values (shown as Pak. Group A) (Figures 2 and 3).

The region of interest in this study consists of several fundamental functional sites such as RNA binding domains (ARM region and HLH region), conserved motif (PESPF) with phosphorylation site at S-177, epitope protein, immunogenic region, clathrin box binding domain, RNA editing or Amber/W site, farnesylation site and isoprenylation site $[2,8,9,11]$.

Multiple sequence alignment (MSA) of clade I predicted amino acid reference sequences and our sequences highlighted some well-conserved regions as well as some amino acid substitutions within critical regions of HDAg protein. Among these fundamental sites, the regions which are crucial for HDV survival including S-177, RNA editing or Amber/W site, immunogenic region and isoprenylation site were found to be highly conserved. However, most of our isolates showed variations in RNA binding domain composed of ARM and HLH region while isolates forming subgroup also show variation in the epitope (Glycine-Proline rich) region (Figure 4).

The MSA revealed that at positions 135 that lie within the HLH region and at position 139 at the start of the ARM region, very little or no variation was present in the reference sequences. At position 142 of the ARM region, amino acid $\mathrm{K}$ predominated in our strains while $\mathrm{E}$ was the main residue in the reference strains. Similarly, amino acid 148 at the beginning of the epitope region of HDAg was more varied $(\mathrm{S}, \mathrm{Q}$ and $\mathrm{R})$ in our strains whereas less variation was seen in the reference sequences (Figure 4).

The potential subgroup named Pak. Isolate group A, which became evident by the ML and Bayesian phylogentic analysis at the nucleotide level showed some unusual patterns of amino acid residues. Among the various amino acid substitutions, the group shows few atypical substitutions that stand out in the alignment. At amino acid 131, the $\mathrm{G}$ residue was predominant in this group while $\mathrm{K}$ residue was more frequent at this site in other strains. In the HDAg protein epitope region, the amino 


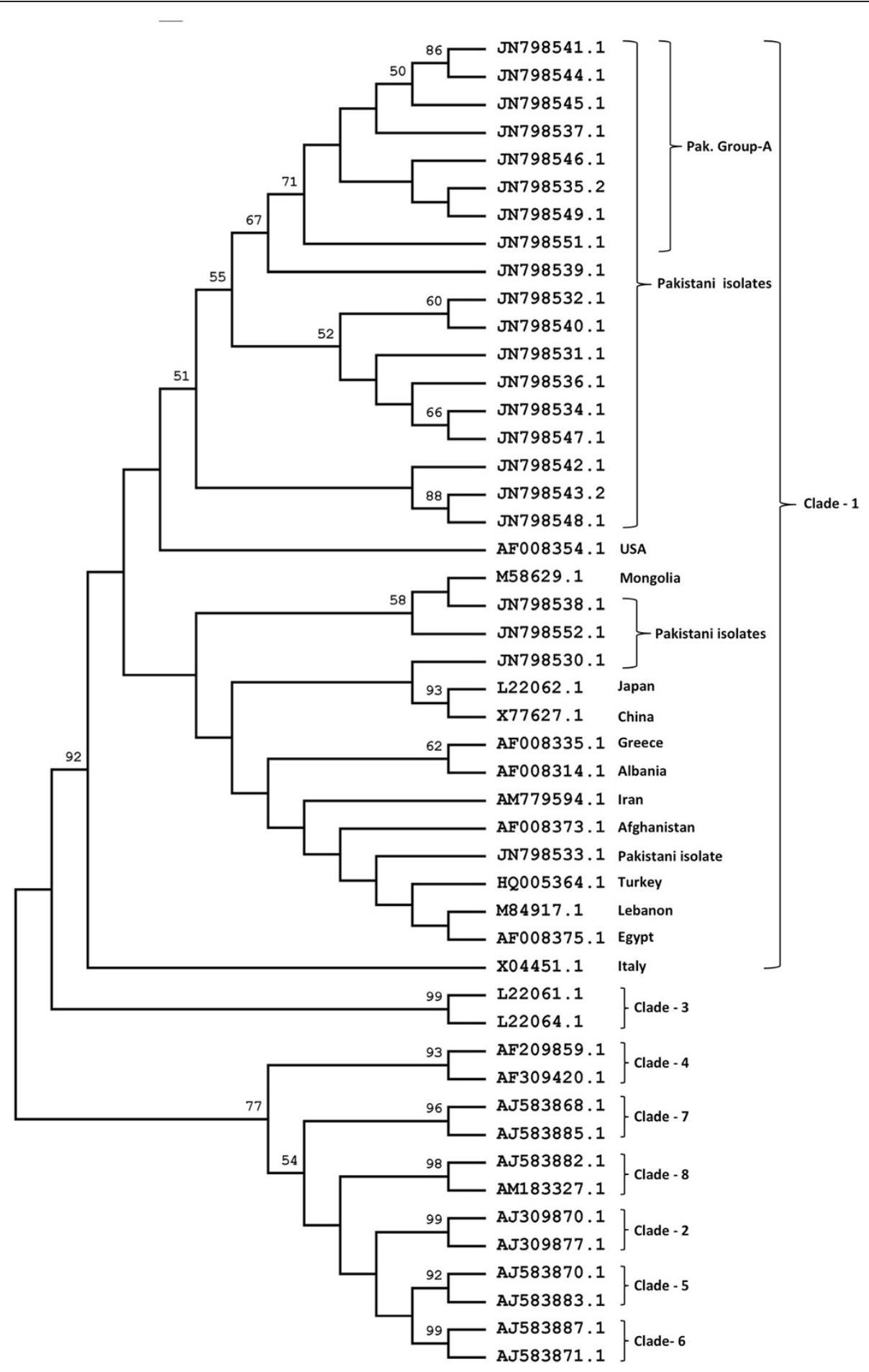

Figure 2 Phylogenetic Analysis of L-HDAg nucleotide sequences from position 856-1282 of isolates from Karachi, Pakistan and reference sequences obtained from GenBank. The analysis was done using the Maximum Likelihood method using the General Time Reversible gamma model, with bootstrap values (1000 replicates), shown next to the nodes of the tree. Evolutionary analyses were conducted in MEGA5.

acid 148 in our sequence alignment showed that this group invariably had $\mathrm{R}$ residue, while $\mathrm{P}$ was the more frequent residue. Position 149 show residue $\mathrm{V}$ in the subgroup consistently, while greater degree of polymorphism was present in our other strains and the reference strains. In the same region, at position 151, residue $D$ dominated in the subgroup while $G$ was the main amino acid in all other strains (Figure 4). Such 


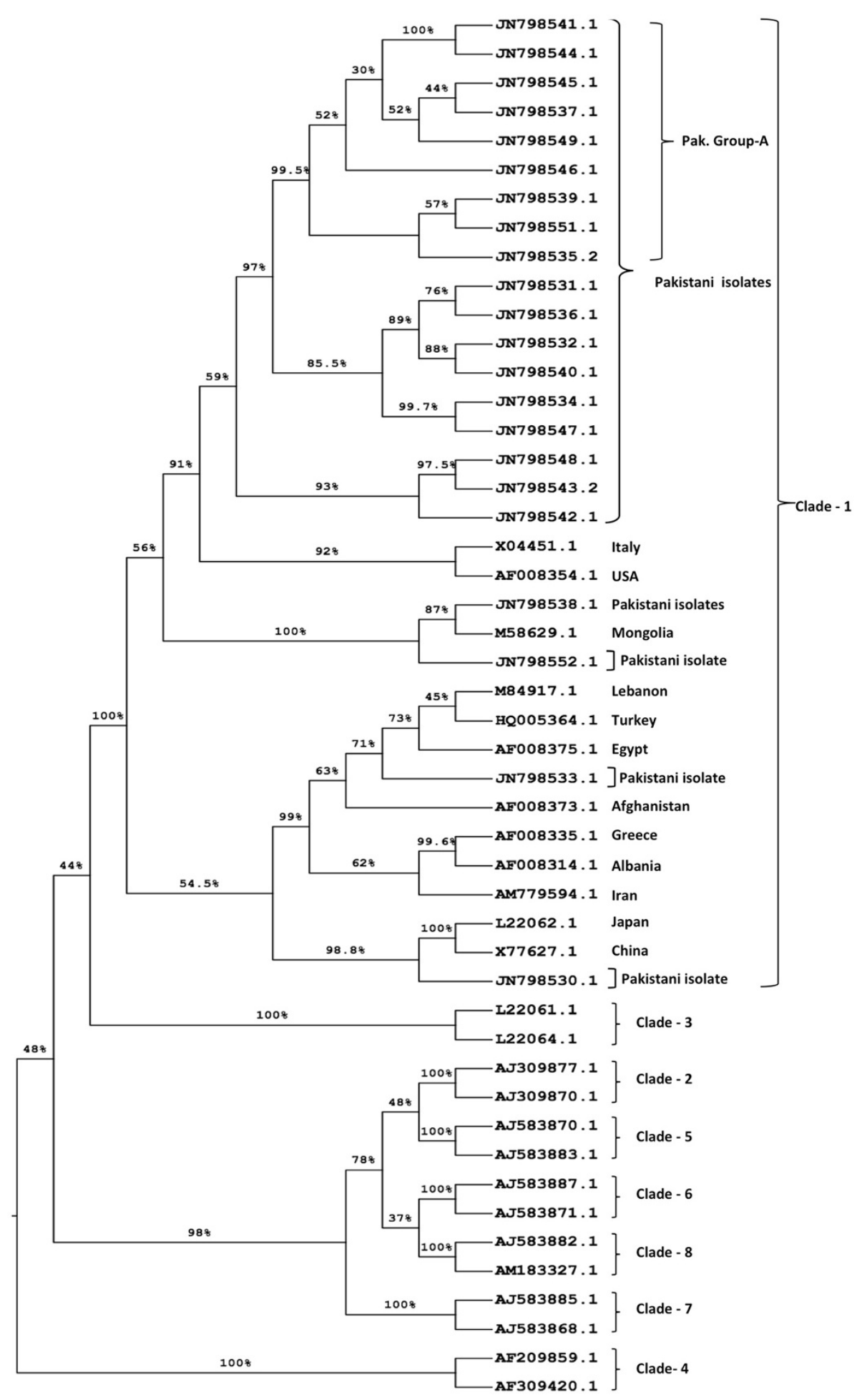

Figure 3 Phylogenetic Analysis of L-HDAg nucleotide sequences from position 856-1282 of isolates from Karachi, Pakistan and reference sequences obtained from GenBank. The analysis was carried out using Bayesian method by applying the Markov Chain Monte Carlo simulation using the software BEAST ver. 1.7.2. The values at the nodes of the tree show the posterior probabilities of the analysis. 


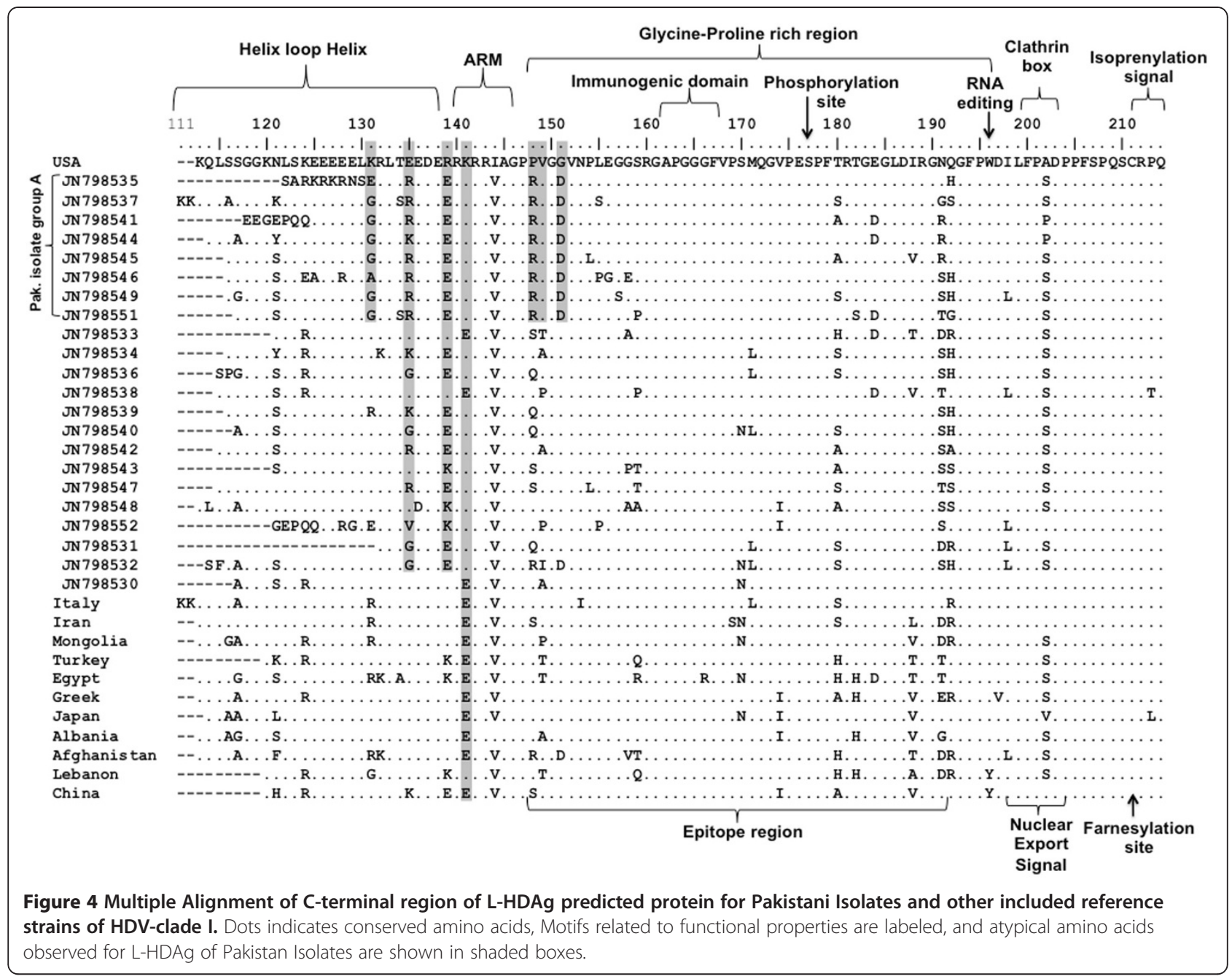

amino acid substitutions have not been reported for HDV in other studies.

Our study clearly shows that most of the isolates obtained from Karachi, Pakistan and its outskirts belong to clade I. This result is in accordance with previous study on HDV genotypic analysis of Pakistan [18]. The clustering of sequences of some of our isolates may point towards formation of a subgroup within clade I. Moreover, the amino acid substitutions discussed above lie in a critical region of HDAg involving RNA replication and packing. Such trends of amino acid substitutions in critical regions of the virus merit further investigation on a large scale supported by extensive clinical studies in order to ascertain their influence on the overall survivability and/or pathogenecity of the virus. Such studies can also determine if these substitutions are hallmark of the HDV strains of the region.

\section{Conclusions}

Phylogenetic analysis of viral genomic sequences can be a forceful approach for the identification of transmission chains in order to control viral epidemics. In our studied isolates we observed a genetic diversity along with formation of potential subgroup within clade I. As viral hepatitis has taken an endemic form in the rural population of Sindh province of Pakistan, it is suggested that studies based on comprehensive demographic information and phylogenetic analysis may lead to provide further information about subgroup formation within clade I. Such studies can be an effective tool in checking and/or preventing the spread of hepatitis $\mathrm{D}$ virus infection.

\section{Methods}

\section{Sample collection and storage}

A study was designed and carried out to determine genotype variants of HDV isolates from the city of Karachi, Pakistan and its outskirts. Whole blood samples were obtained from 22 patients from the outpatient clinics of Dow University of Health Sciences (DUHS). These patients were diagnosed with chronic Hepatitis delta and included 16 males (mean age 32) and 6 females (mean 
age 22). The sampling was carried out under the approval of ethical committee of the institute. All the procedures were explained to the patients and/or their attendants and a written informed consent was obtained for this study. A copy of the written consent is available for review by the Editor-in-Chief of this journal.

About 5 cc of whole blood was collected from each subject in yellow geltop tubes. Serum was separated from whole blood by centrifugation of the geltop tubes at $1200 \mathrm{rpm}$ for 10 minutes. After centrifugation serum was aliquoted and stored at $-80^{\circ} \mathrm{C}$. Related clinical parameters of patients regarding $\mathrm{HBsAg}, \mathrm{HBeAg}$ and $\mathrm{HCV}$ status is presented in Table 1. HBAgs and HCV were evaluated by using an Enzyme -linked immunosorbent assay (ELISA kits, Diasorin S.p.A, Italy).

\section{RNA extraction and reverse transcriptase PCR}

Viral RNA was extracted from $140 \mu \mathrm{l}$ of serum by using QIAamp Viral RNA Mini Kit (Qiagen, Germany). For cDNA synthesis by reverse transcription, $10 \mu \mathrm{l}$ extracted RNA was mixed with $2 \mu \mathrm{l}$ random primers (Fermentas) and denatured at $70^{\circ} \mathrm{C}$ for 10 minutes. To the denatured RNA/random primer, 8U AMV Reverse Transcriptase, (Fermentas), 25U RNAse inhibitor (Fermentas), $2.5 \mathrm{mM}$
dNTPs (Fermentas) was added in a final reaction volume $20 \mu \mathrm{l}$. The reaction was then incubated at $42^{\circ} \mathrm{C}$ for 90 minutes $[17,18]$.

\section{Primer designing}

Pair of outer and inner primers containing both forward and reverse primers for first and second round was designed by using the web-based software Primer 3 [19]. (Table 2) represents the name, position, and sequences of designed primers.

\section{RT-Nested PCR}

One fourth of the synthesized cDNA was used to amplify the HDAg region extending from (856-1282 bp) by Nested PCR. The first round reaction mixture contained $2 \mu \mathrm{l}$ each of $20 \mu \mathrm{M}$ Round- 1 forward and reverse primer, $0.5 \mu \mathrm{l}(2.5 \mathrm{U})$ of Taq DNA polymerase, (Fermentas), $2.5 \mu \mathrm{l}$ of 10X PCR buffer and $1 \mu \mathrm{l}$ of $10 \mathrm{mM}$ dNTPs (Fermentas) in a total reaction volume of $25 \mu \mathrm{l}$. The reaction mix was cycled $94^{\circ} \mathrm{C}$ for 1 minutes (one cycle), $94^{\circ} \mathrm{C}$ for 1 minute, $55^{\circ} \mathrm{C}$ for 1 minutes, $72^{\circ} \mathrm{C}$ for $1 \mathrm{~min}$ ute ( 35 cycles) and $72^{\circ} \mathrm{C}$ for 10 minutes (one cycle).

After completion of the first round of amplification, 4 $\mu \mathrm{l}$ of first round amplified PCR product was transferred

Table 1 Related parameters of hosts (patients) which were the source of the isolated HDV virus

\begin{tabular}{|c|c|c|c|c|c|c|}
\hline Host (patient) Sample ID. & GenBank Accession No & Age & Sex & $\mathrm{HCV}$ & HBsAg/HBeAg status & ALT $(I U / L) *$ \\
\hline DOWKIB336 & JN798530 & 50 & M & No & $+/-$ & 117 \\
\hline DOWKIB359 & JN798531 & 12 & M & No & $+/-$ & 94 \\
\hline DOWKIB306 & JN798532 & 36 & M & No & $+/-$ & 88 \\
\hline DOWKIB262 & JN798533 & 40 & M & No & $+/-$ & 111 \\
\hline DOWKIB331 & JN798534 & 45 & M & No & $+/-$ & 78 \\
\hline DOWKIB300 & JN798535 & 38 & M & No & $+/-$ & 65 \\
\hline DOWKIB335 & JN798536 & 18 & M & No & $+/-$ & 106 \\
\hline DOWKIB319 & JN798537 & 40 & M & No & $+/-$ & 59 \\
\hline DOWKIB320 & JN798538 & 24 & $\mathrm{~F}$ & No & $+/-$ & 127 \\
\hline DOWKIB318 & JN798539 & 26 & $\mathrm{~F}$ & No & $+/-$ & 113 \\
\hline DOWKIB326 & JN798540 & 35 & $\mathrm{~F}$ & No & $+/-$ & 101 \\
\hline DOWKIB342 & JN798541 & 45 & M & No & $+/-$ & 74 \\
\hline DOWKIB314 & JN798542 & 18 & $\mathrm{~F}$ & No & $+/-$ & 134 \\
\hline DOWKIB323 & JN798543 & 14 & $\mathrm{~F}$ & No & $+/-$ & 98 \\
\hline DOWKIB339 & JN798544 & 24 & M & No & $+/-$ & NA \\
\hline DOWKIB313 & JN798545 & 45 & M & No & $+/-$ & 72 \\
\hline DOWKIB327 & JN798546 & 20 & $\mathrm{~F}$ & No & $+/-$ & 67 \\
\hline DOWKIB328 & JN798547 & 18 & M & No & $+/-$ & 127 \\
\hline DOWKIB357 & JN798548 & 34 & M & No & $+/-$ & NA \\
\hline DOEKIB 362 & JN798549 & 21 & M & No & $+/-$ & 63 \\
\hline DOWKIB309 & JN798551 & 30 & M & No & $+/-$ & NA \\
\hline \multirow[t]{2}{*}{ DOWKIB333 } & JN798552 & 25 & M & No & $+/-$ & 82 \\
\hline & \multicolumn{6}{|l|}{ * normal range $10-40 \mathrm{IU} / \mathrm{L}$} \\
\hline
\end{tabular}


Table 2 HDV Primer sequences used for ReverseTranscription Nested PCR

\begin{tabular}{|c|c|c|c|}
\hline \multicolumn{2}{|c|}{ Primer Name } & \multirow{2}{*}{$\begin{array}{l}\text { Primer Sequence; } \mathbf{5} \text { - } \mathbf{3} \\
\text { TCCCTTAGCCATCCGAGTGGAC }\end{array}$} & \multirow{2}{*}{$\begin{array}{l}\begin{array}{l}\text { Position on the } \\
\text { HDV Genome }\end{array} \\
819-840\end{array}$} \\
\hline Round-1 & HDV-1 FOR & & \\
\hline & HDV-1 REV & AGGGTTCACCGACAAGGAGAGG & $1303-1285$ \\
\hline \multirow[t]{2}{*}{ Round-2 } & HDV-2 FOR & GGATGCCCAGGTCGGACCG & $856-875$ \\
\hline & HDV-2 REV & AAGGAAGGCCCTCGAGAACAAG & $1282-1257$ \\
\hline
\end{tabular}

to a new reaction tube for the second round of amplification. The second round nested fragment was amplified under the same conditions described for the first round of amplification $[17,18]$.

Second round amplicons were resolved and screened using 2\% agarose gel electrophoresis method. All PCR reactions were performed with appropriate negative controls to avoid any false positive results.

\section{PCR-RFLP genotyping}

In order to analyze genetic variants of HDV strains, reverse transcriptase nested PCR amplified DNA product of second round was digested with the appropriate restriction enzyme. The reaction mix contained $5 \mu \mathrm{l}$ of the amplified product in $1 \mathrm{X}$ restriction enzyme buffer with $2 \mathrm{U}$ SmaI (Fermentas) restriction enzyme, in a total volume $20 \mu \mathrm{l}$. The reaction mixture was then incubated overnight at $37^{\circ} \mathrm{C}$ and digested products were resolved by electrophoresis on a $3 \%$ agarose gel $[17,18]$.

\section{DNA sequencing}

All nested PCR fragments were purified by PCR cleanup system (Bioneer, Daejeon, Korea) and sent for commercial sequencing. Each PCR products were sequenced in both forward and reverse directions using the Round-2 forward and reverse PCR primers. Sequencing was carried out using the Genetic Analyzer ABI 3300, (Applied Biosystem), at the Centre for Applied Molecular biology CAMB, Lahore, Pakistan. Sequence data of twenty two samples was submitted to the NCBI GenBank and are available as accession numbers JN798530 to JN798549, JN798551 and JN798552.

\section{Nucleotide sequence analysis}

Twenty six nucleotide sequences of HDAg coding (R0) region were obtained from GenBank to use as reference sequences, for phylogenetic analysis. The DNA sequences were chosen such that they represented the eight clades of HDV, with more sequences belonging to clade I. Twelve sequences belonged to clade I while fourteen belonged to clade II to clade VIII.

\section{Phylogenetic analysis}

First, a multiple sequence alignment (MSA) was carried out for all C-terminal L-HDAg coding DNA sequences using ClustalW2 function of MEGA software version 5.0 (MEGA 5) [20]. The MSA included sequences from the new HDV isolates and reference sequences from GenBank. The default gap opening penalty (GOP) of 15 and gap extension penalty (GEP) of 6.66 were used. The MSA was then checked and edited manually for any inconsistency in the homologous alignment, using the alignment explorer window of MEGA 5. The program jModeltest version 0.1.1 [21] was used to determine the nucleotide substitution model and parameters that best fitted the dataset according to Akaike Information Criterion (AIC) and Bayesian Information Criterion (BIC). The general time reversible model with gamma distribution $(G T R+G)$ was then used to create a maximum likelihood (ML) tree using MEGA 5.0, with bootstrap resampling (1000 replicates) in order to confirm reliability of phylogenetic tree. A Bayesian phylogenetic analyses (using GTR + G model) was also done by applying Markov Chain Monte Carlo simulation using the software BEAST v.1.7.2 [22]. The MCMC chain ran for 10 million states and sampled every 1000 states, with $10 \%$ burn-in. The results were examined in the software Tracer v1.5 [23], which showed an effective sample size (ESS) of $>300$ indicating a better convergence of all parameters. The maximum clade credibility (MCC) tree was obtained by using TreeAnnotator in the BEAST package [22]. Trees were visualized using the FigTree v1.3.1 program [24].

\section{Amino acid sequence analysis}

For amino acid sequence analysis, the twenty two nucleotide sequences of the local isolates were translated by using ExPasy online tool [25]. The predicted amino acid sequences from the twelve clade I nucleotide sequences used in the phylogenetic analysis were obtained from GenBank. Multiple sequence alignments of the 34 amino acid sequences were performed using ClustalW2 function of MEGA 5, in order to delineate the consensus sequences. The predicted protein sequence of the nucleotide sequence AF008354.1 (shown as USA in Figure 4), was chosen as a base reference for the amino acid MSA due to its closeness with most of our isolates in the nucleotide phylogenetic tree.

\section{Competing interests}

The authors declare that they have no competing interests.

\section{Authors' contributions}

SP searched the literature, performed the benchwork and drafted the manuscript, IN helped in the sample collection, provided the optimized protocols and methods, SMS participated in sample collection and analysis of biochemical parameters of patients. AA analyzed the data and helped in 
paper write up. OYK designed the study and critically viewed the manuscript. All authors have read and approved the final manuscript.

\section{Acknowledgements}

The research work was funded by the Karachi Institute of Biotechnology \& Genetic Engineering (KIBGE), University of Karachi, Karachi-Pakistan. DNA sequencing was funded by Higher Education Commission, Pakistan (HEC) under the research and development "Access to scientific instrumentation programme". We thank clinical and laboratory staff of DOW University of health sciences for sample collection.

\section{Author details}

${ }^{1}$ The Karachi Institute of Biotechnology \& Genetic Engineering (KIBGE), University of Karachi, Karachi, Pakistan. ${ }^{2}$ Dow University of Health Sciences (DUHS), Karachi, Pakistan. ${ }^{3}$ Department of Genetics, University of Karachi, Karachi, Pakistan.

Received: 31 January 2012 Accepted: 7 August 2012

Published: 15 August 2012

\section{References}

1. Hepatitis D [http://www.who.int/csr/disease/hepatitis/whocdscsrncs20011/ en/index5.html].

2. Farci P: Delta hepatitis: an update. J Hepatol 2003, 39(Suppl 1):S212-219.

3. Hepatitis D Virus [http://www.stanford.edu/group/virus/delta/2005/].

4. Huang CR, Lo SJ: Evolution and diversity of the human hepatitis D virus genome. Advances in Bioinformatics 2009, 2010:1-9.

5. Deny P: Hepatitis delta virus genetic variability: from genotypes I, II, III to eight major clades? Curr Top Microbiol Immunol 2006, 307:151-171.

6. Pascarella S, Negro F: Hepatitis D virus: an update. Liver International 2011, $31: 7-21$.

7. Casey JL: RNA editing in hepatitis delta virus. Curr Top Microbiol Immunol 2006, 307:67-89.

8. Shakil AO, Hadziyannis S, Hoofnagle JH, Di Bisceglie AM, Gerin JL, Casey U: Geographic distribution and genetic variability of hepatitis delta virus genotype I. Virology 1997, 234:160-167.

9. Lai MM: Hepatitis Delta Antigen: Biochemical Properties and Functional Roles in HDV Replication. In Hepatitis Delta Virus. Edited by Handa H, Yamaguchi Y.: Springer; 2006:38-51.

10. Wang JG, Jansen RW, Brown EA, Lemon SM: Immunogenic domains of hepatitis delta virus antigen: peptide mapping of epitopes recognized by human and woodchuck antibodies. J Virol 1990, 64:1108-1116.

11. Greco-Stewart V, Pelchat M: Interaction of Host Cellular Proteins with Components of the Hepatitis Delta Virus. Viruses 2010, 2:189-212.

12. Radjef N, Gordien E, Ivaniushina V, Gault E, Anais P, Drugan T, Trinchet JC, Roulot D, Tamby M, Milinkovitch MC, Deny P: Molecular phylogenetic analyses indicate a wide and ancient radiation of African hepatitis delta virus, suggesting a deltavirus genus of at least seven major clades. J Virol 2004, 78:2537-2544

13. Casey JL, Gerin JL: Genotype-specific complementation of hepatitis delta virus RNA replication by hepatitis delta antigen. J Virol 1998, 72:28062814.

14. Abbas Z, Jafri W, Raza S: Hepatitis D: Scenario in the Asia-Pacific region. World J Gastroenterol 2010, 16:554-562.

15. Khan AU, Waqar M, Akram M, Zaib M, Wasim M, Ahmad S, Niaz Z, Ali S, Ali $\mathrm{H}$, Idrees M, Bajwa MA: True prevalence of twin HDV-HBV infection in Pakistan: a molecular approach. Virol J 2011, 8:420.

16. Bosan A, Qureshi H, Bile KM, Ahmad I, Hafiz R: A review of hepatitis viral infections in Pakistan. J Pak Med Assoc 2011, 60:1045-1058.

17. Cakaloglu Y, Akyuz F, Bozaci M, Ibrisim D, Pinarbasi B, Demir K, Kaymakoglu S, Besisik F, Badur S, Okten A: Prevalence and clinical significance of SEN-H virus in chronic hepatitis B, C and delta infections in Turkey. Turk J Gastroenterol 2008, 19:104-108.

18. Moatter T, Abbas Z, Shabir S, Jafri W: Clinical presentation and genotype of hepatitis delta in Karachi. World J Gastroenterol 2007, 13:2604-2607.

19. Primer 3 [http://primer3.sourceforge.net/history.php].

20. Tamura K, Peterson D, Peterson N, Stecher G, Nei M, Kumar S: MEGA5: molecular evolutionary genetics analysis using maximum likelihood, evolutionary distance, and maximum parsimony methods. Mol Biol Evol 2011, 28:2731-2739.
21. D P: jModelTest.Phylogenetic Model Averaging. Molecular Biology and Evolution 2008, 25:1253-1256.

22. Drummond AJ, Rambaut A: BEAST: Bayesian evolutionary analysis by sampling trees. BMC Evol Biol 2007, 7:214.

23. Rambaut A, Drummond AJ: Tracer v1.5. 2009. Available from http://beast.bio. ed.ac.uk/Tracer. Accessed 24 July 2012.

24. Rambaut A: FigTree v1.3.1: Tree figure drawing tool. 2008. Available: http:// tree.bio.ed.ac.uk/software/figtre?e/. Accessed 24 July 2012

25. ExPASy - Translate tool [web.expasy.org/translate/].

\section{doi:10.1186/1743-422X-9-162}

Cite this article as: Perveen et al:: Phylogenetic analysis of HDV isolates from HBsAg positive patients in Karachi, Pakistan. Virology Journal 2012 9:162.

\section{Submit your next manuscript to BioMed Central and take full advantage of:}

- Convenient online submission

- Thorough peer review

- No space constraints or color figure charges

- Immediate publication on acceptance

- Inclusion in PubMed, CAS, Scopus and Google Scholar

- Research which is freely available for redistribution

Submit your manuscript at www.biomedcentral.com/submit 